UDC [316.77:004]:2-4

LBC 86.29-16.6

\title{
RELIGIOUS PRACTICES ONLINE: BELARUS EXPERIENCE
}

\author{
Dmitry K. Beznjuk \\ Institute of Sociology of the National Academy of Sciences of Belarus, Minsk, Republic of Belarus \\ Natalya V. Tsybulskaya \\ Institute of Sociology of the National Academy of Sciences of Belarus, Minsk, Republic of Belarus
}

\begin{abstract}
The authors deal with the problems of transformation of religion in the information society, in particular, the modification of religious practices updated on the Internet. Digitalization appears in modern society and culture not only as a technical and technological phenomenon, but also as a socio-cultural challenge, which is to be answered by the religious sphere. Under the influence of the global process of digitalization religion, as one of the forms of public consciousness, finds and implements innovative ways of practice. In the structure of these practices, as the authors show in the article, the information and communication element is the most suitable for digitalization. The article reveals the content of the concept of "religious practices" as a continuation of the evolutionary chain of development and transformation of meanings originating in social philosophy: social action - social communication - social practices. The researchers consider the essence of the main provisions of the theory of practices by Theodore Shatsky. The paper reveals the essence of religious practices, describes their features, presents typologies of religious practices on various grounds. The division of social practices into conventional and innovative (according to V. Radaev) as a variant of assessing the prospects and orientation of digitalization in the religious sphere is approved. The phenomenon of digitalization of religious practices is associated with new opportunities to meet the religious needs of the believer. The authors give some examples of digitization of religious practices in foreign religious communities, which demonstrate the capabilities and technological features of this process, reveal its content and likely social consequences. The paper describes the main characteristics of the religious field of modern Belarus, in order to understand the conditions of digitization of religious practices and the presentation of the national and historical specifics of Belarus. The researchers give a brief overview of the representation of religious organizations in Minsk on the Internet (due to the greatest representativeness of religious diversity). They suggest the results of the analysis of the sites of religious communities in Minsk, which make it possible to assess the degree and results of digitization of the religious sphere of Belarus, the readiness of religious organizations to operate in the digital space, the scale of consumption of digital religious products.
\end{abstract}

Key words: religion, practice, digitalization, behavior, action, confessions, website, Internet.

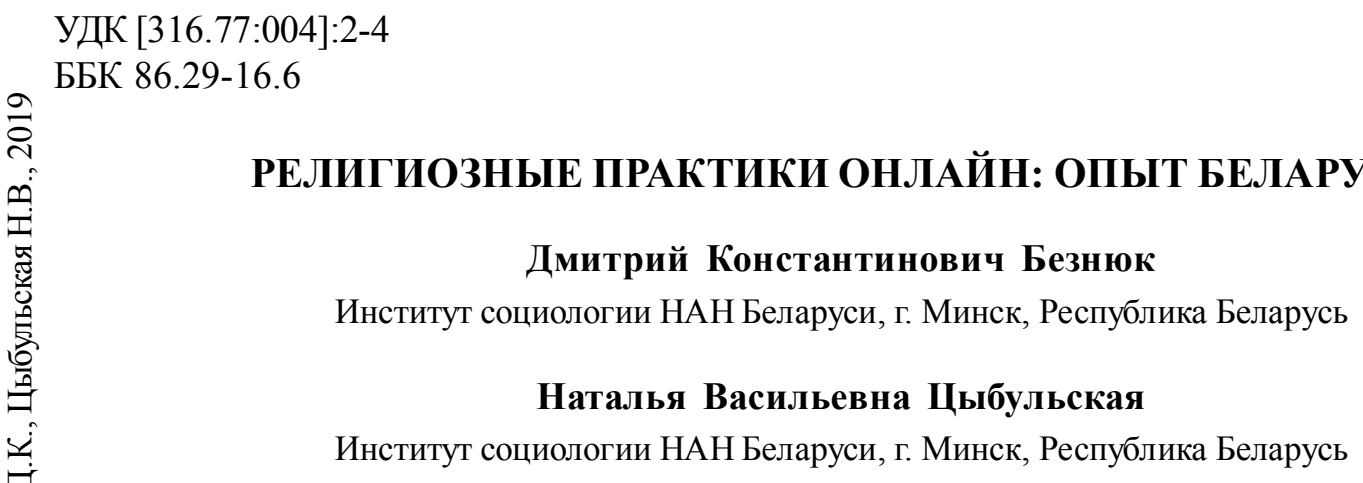

Аннотация. В статье рассматриваются проблемы трансформации религии в условиях информационного общества, в частности - видоизменение религиозных практик, актуализируемых в Интернете. Цифровизация предстает в современном обществе и культуре не только как технико-технологический феномен, но 


\section{БЕЛОРУССКАЯ АКАДЕМИЧЕСКАЯ СОЦИОЛОГИЯ}

и как социокультурный вызов, на который необходимо ответить и религиозной сфере. Под влиянием глобального процесса цифровизации религия как одна из форм общественного сознания находит и реализует инновационные способы практик. В структуре этих практик, как показано в статье, наиболее подходящим для цифровизации оказывается информационно-коммуникативный элемент. В статье раскрывается содержание понятия «религиозные практики» как продолжение эволюционной цепочки развития и трансформации смыслов, берущих свое начало в социальной философии: социальное действие - социальная коммуникация - социальные практики. Рассматривается суть основных положений теории практик Теодора Шацки. Выявлена сущность религиозных практик, описаны их признаки, представлены типологии религиозных практик по различным основаниям. Утверждается деление социальных практик на обычные и инновационные (по В. Радаеву) как вариант оценки перспективности и направленности цифровизации в религиозной сфере. Сам феномен цифровизации религиозных практик связывается с новыми возможностями удовлетворения религиозных потребностей верующего. Приводятся некоторые примеры цифровизации религиозных практик в зарубежных религиозных сообществах, которые демонстрируют возможности и технологические особенности этого процесса, раскрывают его содержание и вероятные социальные последствия. Описаны основные характеристики религиозного поля современной Беларуси с целью понимания условий цифровизации религиозных практик и презентации национальной и исторической специфики Беларуси. Дается краткий обзор представленности в Интернете религиозных организаций города Минска (в силу наибольшей репрезентативности религиозного разнообразия). Приведены результаты анализа сайтов религиозных общин Минска, которые дают возможность оценить степень и результаты цифровизации религиозной сферы Беларуси, готовность религиозных организаций к деятельности в цифровом пространстве, масштабы потребления цифровой религиозной продукции.

Ключевые слова: религия, практика, цифровизация, поведение, действие, конфессии, сайт, Интернет.

Цифровизация сегодня стала реальным (историческим) и интеллектуальным (научнотеоретическим) трендом. По своим масштабам цифровизация сродни глобализации - она проникает во многие сегменты социального пространства, кардинально меняет характер и содержание культурных практик, трансформирует лицо нашей цивилизации. Многие развитые государства делают ставку на цифровизацию экономики, разрабатывают программы цифровизации отдельных секторов социальной и культурной сферы.

Основными феноменами современных процессов цифровизации в социокультурной сфере являются широко распространенные цифровые устройства - персональные компьютеры, ноутбуки, планшеты, смартфоны и т. п., при помощи которых традиционные формы коммуникации можно осуществлять новыми, цифровыми способами: использовать социальные сети и мессенджеры, читать книги в электронном формате, просматривать оцифрованные фотографии, прослушивать «в цифре» аудиозаписи и просматривать видео и телевизионные программы. Цифровые коммуникации приобрели массовый и глобальный характер. Носители цифровой информации приобретают характеристики персональности и мобильности. Технологии цифровой коммуни- кации становятся простыми, а цифровые устройства - легко управляемыми: для того чтобы их освоить, не требуется специальной долговременной подготовки.

В культурно-философском аспекте цифровое общество представляется как новая форма бытия, «третья природа» (традиционно под «второй природой» понимается «культура» в целом), продолжающая естественную среду обитания и «мир вещей».

В силу своей масштабности и инклюзивности цифровизация не обходит стороной и религию - сферу, казалось бы, наиболее нематериальную и интимную. Как справедливо замечает российская исследовательница А.В. Конева, «дигитальное пространство ставит перед религией не просто вызовы технико-технологического, но и метафизического порядка, заставляя переосмысливать изначальные авторитеты и ценности и вслед за этим находить иные способы практик» [Конева 2018, 67].

Анализ феномена цифровизации (дигитализации) современных религиозных практик следует начинать с прояснения понятия «религиозные практики», по поводу которого идут постоянные дискуссии, происходят уточнения и семантические коррекции.

Как представляется, смысловое поле изучения религиозных практик задается не- 
сколькими фундаментальными понятиями, начала которых лежат в современной социальной теории. Эти понятия можно представить в эволюционной цепочке, отражающей развитие и трансформацию смыслов, приведших к нынешним религиоведческим дискурсам: социальное действие - социальная коммуникация - социальные практики.

Слово «практика» широко используется не только в повседневном языке, но и в социогуманитарных науках. Во втором случае, говоря о термине «практика», следует отметить его недостаточную разработку в современной русскоязычной научной литературе. Достаточно часто авторы используют это понятие интуитивно, подразумевая актуализацию человеком неких смыслов, установок, традиций в самых различных сферах повседневной жизнедеятельности.

В зарубежной социологии концептуализации практик содержатся в трудах П. Бурдье, Э. Гидденса, Г. Гарфинкеля, М. Фуко и других ученых. Одна из версий теории практик разработана американским социальным философом Теодором Шацки (Theodore R. Schatzki), творчество которого соотносят со «вторым поколением» исследователей практик. Мыслитель на протяжении последних двадцати лет развивает аналитическую схему и категориальный аппарат своей версии теории практик, проводя параллели в том числе и с «классическими» исследованиями практик. Например, T. Шацки находит сходства с элементамиорганизаторами практик у П. Бурдье (габитус, ставки, капиталы) и Э. Гидденса (наборы правил и ресурсов). Однако версия теории практик Т. Шацки отличается от «классических» социологических концептуализаций практик П. Бурдье и Э. Гидденса (популярных у исследователей культурных практик), прежде всего, концептуальным аппаратом, а также фокусированием на материальных, время-пространственных, процессуальных моментах реализации практик.

Кратко обобщая суть основных положений теории практик Т. Шацки, украинский социолог Наталия Ковалиско передает суть дефиниции понятия «практики» следующим образом: практики (религиозные, политические, экономические, приготовления пищи и т. п.) это «сложные образования, в которых разли- чают комплекс пониманий, адекватных действиям, коллекцию правил и «телеоаффективную структуру», то есть нормативную, иерархически упорядоченную систему целей, проектов, задач, эмоциональных состояний». [Theodore R. Schatzki 2003, 191-192]. В теории практик Т. Шацки пространство взаимодействий между людьми представлено как мир самых различных практик (и физических действий, и ментальных конструкций), взаимопроникающих одна в другую и образующих плотную сеть [Ковалиско 2010, 52].

Российский социолог Татьяна Заславская указывает на то, что совокупность актуализирующихся социальных практик в какой-либо сфере социальной жизни - это и есть общая форма реализации деятельности соответствующего института [Заславская 2000, 15]. Другими словами, общепринятые социальные практики в определенный момент времени начинают представлять собой результат институциональных изменений. По мнению Н. Ковалиско, этим обстоятельством утверждается деление практик на обычные (традиционные) и новые (инновационные) [Ковалиско 2010, 55]. Так, существующие религиозные практики все в большей мере определяются цифровыми новациями современного общества.

Российский социолог и экономист Вадим Радаев называет обычными практиками достаточно распространенные типичные действия людей, в которые вовлечена большая часть населения, и эти действия практикуются в течение жизни минимум одного поколения [Paдаев 2003, 90]. Н. Ковалиско, соглашаясь с В. Радаевым, определяет инновационные практики как «типичные действия людей, с одной стороны, не очень широко распространенные... но уже весьма заметные, а с другой стороны, являющиеся новыми способами действий», которые, к примеру, еще десять лет назад существовали в ограниченных масштабах, либо их не было совсем [Ковалиско 2010, 56].

Для иллюстрации можно привести пример из религиозных практик. Молиться - весьма распространенное занятие среди христиан, и значительная их часть обычно (традиционно) молится в храме или дома, читая текст молитвы наизусть, повторяя за священником или пользуясь текстами из бумажной 
книги-молитвенника. Молитва же перед телевизором или экраном монитора, на которых с использованием субтитров транслируется богослужение или коллективная молитва в храме, - это практика инновационная - цифровая практика, которая появилась сравнительно недавно и существует гораздо меньше времени жизни одного поколения людей.

Опираясь на теоретические разработки в области социального действия и социальных практик, можно выстроить своеобразный понятийный четырехугольник, который и задает пространство, в котором происходит продуцирование научных смыслов по поводу религиозных практик: религиозное действие - религиозное поведение - религиозный опыт - peлигиозная практика.

Религиозное действие выступает базовым понятием, по аналогии с социальным действием. Впервые этот термин, по всей вероятности, употребил Гегель в своей работе «Дух христианства и его судьба» (1798-1800). Несмотря на то что гегелевская интерпретация его содержания (относительно Тайной вечери) вызывает вопросы, понятие было запущено в научный оборот.

Российская исследовательница Л.С. Астахова определяет религиозное действие «как совокупность социальных актов, мотивированных религиозно (либо направленных на удовлетворение соответствующих потребностей)» [Астахова 2008, 33]. Религиозное действие можно считать базовым элементом любой социальной практики. Л.С. Астахова настаивает на том, что религиозное действие отличается от социального действия направленностью: первое не предусматривает в обязательном порядке ориентацию на социум.

Л.С. Астахова выделяет универсальные характеристики религиозного действия:

- религиозное действие носит субъективный характер, так как исходит из личной трактовки смыслов, вкладываемых в религиозное действие;

- религиозное действие реалистично в том смысле, что это всегда переживание живых, реальных действий;

- религиозное действие связано с нормативной ориентацией;

- религиозное действие выражает одностороннюю активность [Астахова 2008].
Религиозное поведение будет выступать более широким феноменом по отношению к религиозному действию, так как представляет собой совокупность самых разнообразных действий и поступков субъекта в соответствии с нормами и стандартами его веры. Религиозное поведение суть материализация символического нормативно-ценностного мира верующего человека.

Сопровождающий религиозное поведение религиозный опыт выступает, пожалуй, самой субъективной, сокровенной и плохо фиксируемой (объективным наблюдателем) характеристикой жизни верующего. Религиозный опыт принято понимать как сопричастность нуминозному, как непосредственное переживание сакрального, как совокупность внутренних психоэмоциональных состояний (следствий) встречи со священным, что формирует личность верующего и его когнитивный (в рамках религиозной веры) комплекс.

Религиозная же практика может быть представлена как синтезирующее свойство вышеописанных понятий: она и объективирует религиозные чувства, смыслы, опыт (в силу соотнесенности с традицией и ритуалом), и допускает субъективизацию оных (в силу привходящих, экзистентных, ситуативных моментов). Как справедливо замечает Л.С. Астахова, «религиозные практики как деятельностные феномены современной религиозной жизни являются точкой пересечения доктринальной закрытости религиозных институтов и спонтанной реакции обыденного сознания в структурах повседневности на быстрые изменения социальных условий» [Астахова 2013, 9]. А. Агаджанян и К. Русселе, отмечая сложность феномена религиозных практик, предлагают его дуальную дефиницию: статическое определение (это «вся совокупность интерпретаций и действий, совершаемых людьми в связи с их верованиями, их религиозным опытом и/или их взаимодействием с религиозными институтами») и определение динамическое (это «явление, противоположное жесткой системе религиозных текстов, норм, институтов, как постоянный “герменевтический процесс" их переосмысления и прикладного корректирования») [Русселе, Агаджанян (ред.) 2006, 3]. 
Религиозная практика отражает принципиально дуальный характер верующего человека, на что обращал внимание еще Э. Дюркгейм, когда говорил о раздвоенности мира в сознании верующего на профанный и сакральный компоненты. Отсюда один из наиболее распространенных вариантов понимания природы религиозной практики как «области, где в символической форме происходит взаимодействие сакрального и повседневного, или социального, пространства человека» [Русселе, Агаджанян (ред.) 2006, 194].

На вопрос, что вызывает к жизни религиозные практики, можно, пожалуй, ответить так: религиозные потребности. В этой связи религиозные практики можно представить как реальные и многообразные формы реализации религиозных потребностей.

Говоря о сущности религиозных практик, становится ясно, что она раскрывается во множестве признаков и свойств, отражающих ее комплексный и диалектический характер функционирования. К таковым признакам следует отнести:

- связывание миров: в рамках религиозной практики происходит соединение профанного и сакрального миров, агент практики символически переходит из одного мира в другой, создает свой неповторимый религиозный хронотоп;

- технологичность: религиозной практике как действию свойственна алгоритмичность (цель, средства, сценарий, путь, правила), что привязывает ее к миру институций, ранее установленных и одобренных стандартов - официальному вероучению, например;

- ориентацию: религиозная практика может подразумевать не только ориентацию на священное, но и на социальный мир, на других людей (частный случай социального действия);

- коммуникативный характер: религиозной практике (даже если принять тезис о ее однонаправленности) необходимо коммуникационное оформление;

- реактивность: религиозные практики, как показывает история религий, носят пластичный характер - они способны к изменениям, к рождению, к трансформации; они суть реакция на изменение социальной среды в религиозно-символической форме, реакция на потребность в живом религиозном опыте (здесь можно вспомнить, что П. Бурдье все практики трактовал как изменение агентом окружающего социального мира).

Выделенные признаки ценны для нашего исследования тем, что относительно каждого из них можно в будущем попытаться установить, так сказать, потенциал цифровизации - насколько признак религиозной практики способен быть подвержен «оцифровке» и как это скажется на его субстанциональной и функциональной составляющей, как это отразится на характере религиозной практики в целом.

Мы уже отмечали, что религиозные практики, как и религиозный опыт, весьма разнообразны и по своему содержанию обладают разным потенциалом цифровизации. Для религиоведения важно установить и прояснить различные виды религиозных практик, хотя это задача трудновыполнимая и сопровождающаяся постоянными дискуссиями, в ходе которых рождаются новые типологии и классификации. На сегодняшний день религиоведы оперируют следующими схемами описания разнообразия религиозных практик:

1. По характеру действий: культовые или собственно религиозные практики (связаны с богослужением, теопраксия) и не(вне)культовые практики (не имеют прямого отношения к культовой деятельности: чтение религиозных и нравственно-назидательных книг, конфессиональных СМИ, участие в социальных мероприятиях своей общины и пр.). Иногда эта классификация производится с помощью понятий «религиозные практики» и «околорелигиозные практики».

2. По нормативной ориентации: институционализированные (регламентированные) и «новые» (событийно-ситуативные).

3. По субъекту (агенту): общие (общинные, общецерковные), групповые (семейные, например) и личные религиозные практики. В сокращенном варианте эту классификацию можно представить так: групповые и индивидуальные религиозные практики.

4. По шкале вовлеченности в структуры повседневности: доктринальные, опытные и ситуативные практики (Л.С. Астахова).

5. По доминирующей социальной ориентации (или по масштабу): ориентированные на сугубо сакральное (несоциальные практики), 


\section{БЕЛОРУССКАЯ АКАДЕМИЧЕСКАЯ СОЦИОЛОГИЯ}

ориентированные на все общество, на отдельные институты, на религиозную организацию, на отдельных верующих.

Уровень развития цифровых технологий в современном обществе предоставляет широкие возможности их использования в процессе реализации религиозных практик. Работа церкви и IT-компаний в этом направлении сегодня позволяет внедрить цифровые способы выполнения многих функций, необходимых для обеспечения религиозной жизни верующих: от внесения безналичных пожертвований до повышения степени удобства участия в богослужении, организации онлайн-коммуникаций с единомышленниками.

Приведем некоторые примеры цифровизации религиозных практик в зарубежных религиозных сообществах. В 2015 г. в 100 пунктах сбора пожертвования представители Армии спасения - международной христианской (методистской) организации - стали использовать устройство DipJar для кредитных карт. Процесс оставления пожертвований можно было и услышать: при переводе суммы пожертвования устройство издавало характерный звук падающих монет.

Новые технологии активно используются во время богослужений в храмах США. Некоторые церкви устанавливают светодиодные стены для передачи визуальных эффектов во время проповеди, популярна установка видеостен или проекторов для показа иллюстраций к проповедям, давно используются динамики для усиления звука. Устанавливаются интерактивные экраны для проведения евангелизационных онлайн-встреч. В домах молитвы появляются высокотехнологичные конференц-залы. Церкви приглашают прихожан работать в своих помещениях, привлекая высокоскоростным Wi-Fi, уютом и тишиной.

В настоящее время компании активно разрабатывают и предлагают общинам приложения для гаджетов. Подобные сервисы позволяют управлять регистрацией верующих, отслеживать статистику посещаемости, отправлять напоминание пасторам и прихожанам, создавать календарь церковных мероприятий. Через них прихожане также могут вносить пожертвования, поддерживать связь со своей группой по изучению Библии, прослу- шивать и просматривать проповеди, некоторые приложения позволяют смотреть онлайнтрансляцию богослужения, а также задавать вопросы по ходу богослужения. Сегодня церкви Запада все более охотно приглашают на работу не секретарей, а IT-специалистов и заключают контракты с компаниями по техническому обслуживанию [Церкви... web].

Таким образом, активное использование цифровых технологий для работы с прихожанами и евангелизации изменяет формат проведения богослужений, пространство храмов, организацию деятельности общин.

Если диагностировать уровень цифровизации религиозной сферы Республики Беларусь, то начать, пожалуй, стоит с констатации некоторых фундаментальных характеристик религиозного поля современной Беларуси.

1. Конфессиональная структура Беларуси может быть представлена следующей моделью: доминирующее христианство (с очень динамичным неопротестантским элементом) и широкий спектр иных конфессий (с незначительным числом сторонников новых, нетрадиционных религий).

2. Уровень религиозности населения и его воцерковленности: относят себя к верующим более $80 \%$ населения, но регулярно посещают богослужения и совершают обряды около 10 \% [Религия в Беларуси... web]. Среди белорусских верующих, прежде всего это касается традиционных религий, преобладают так называемые партикулярные верующие.

3. Исторически сложившаяся и естественная конфессиональная пестрота: на 2019 г. в Республике Беларусь официально зарегистрировано 25 конфессий. Традиционными религиозными направлениями официально признаются православие, римо-католичество, лютеранство, иудаизм и ислам.

Более $70 \%$ верующих белорусов относят себя к православным, $12 \%$ - к католикам, около $12 \%$ - к другим конфессиям [Религия в Беларуси... web]. Конфессиональная пестрота в Беларуси имеет достаточно ярко выраженную национально-этническую окраску. Заметными элементами национальной конфессиональной структуры являются полякикатолики, немцы-лютеране, русские-староверы, татары-мусульмане. 
4. В Республике действуют 3524 религиозных организации, из них 174 организации имеют общеконфессиональное значение (религиозные объединения, монастыри, миссии, братства, сестричества, духовные учебные заведения) [Общество web].

Для анализа заявленной темы исследования авторы выбрали религиозные организации Минска в силу наибольшей репрезентативности религиозного разнообразия - в столице зарегистрированы сторонники двадцати одной конфессии, которые представлены 153 религиозными организациями.

Около $80 \%$ религиозных организаций Минска представлены в Интернете собственными сайтами, многие из них имеют аккаунты в таких социальных сетях, как Фейсбук, ВКонтакте, Твиттер, Инстаграм, YouTube. Ocтальные почти $20 \%$ религиозных организаций не имеют собственных сайтов, однако информацию о деятельности большинства из них можно найти на сайтах религиозных объединений, в которые они входят. Исключениями являются несколько организаций:

1) община Армянской апостольской церкви «Святой Григорий Просветитель» (не имеет своего храма). Сведения об общине имеются на светском сайте http://miasin.by («Миасин» - интернет-газета армянской общины Республики Беларусь);

2) религиозная община «Древлеправославный приход в честь Архангела Михаила и прочих святых небесных сил бесплотных» (не имеет своего храма). Община никак не проявляет себя в информационном пространстве;

3) религиозная евангелическо-лютеранская община «Церковь Креста Господня» (нет сведений о храме) не проявляет информационной активности; сайт Самостоятельной Евангелической лютеранской церкви в Республике Беларусь (http://selk.by) недоступен пользователям, а на странице церкви в Facebook последняя запись датирована 2016 годом.

Анализ сайтов религиозных общин Минска в контексте цифровизации религиозных практик показал, что почти все сайты содержат следующие рубрики:

- контактная информация;

- сведения о богослужениях, литургический календарь, праздники;
- история своей организации и/или своего вероучения (конфессии);

- анонсы и отчеты о проводимых мероприятиях;

- сведения о руководителях организации;

- документы (рубрика характерна для официальных сайтов крупных конфессий);

- миссионерская деятельность;

- социальное служение;

- рубрика «Задать вопрос»;

- библиотека/тексты (вероучительные, назидательные, богослужебные).

Большинство указанных рубрик нацелены на сбор и распространение религиозной информации, а также (в меньшей степени) на коммуникацию между священниками и верующими, в чем и состоят преимущества Интернета в отличие от обычных СМИ: обеспечение немедленного доступа к религиозным и духовным источникам, к оцифрованным собраниям библиотек, музеев, к виртуальным экскурсиям в места культа, а также предоставление возможности верующим формировать виртуальные общины для религиозного общения.

Кроме создания и обеспечения деятельности информационных сайтов и порталов, религиозные организации в Беларуси «осваивают» интернет-пространство и для других целей. На современном этапе актуализации инновационных религиозных практик католические общины проявляют бо́льшую активность по сравнению с представителями других религий и конфессий. Приведем несколько примеров.

6 марта 2019 г. на портале catholic.by появился модуль электронной оплаты пожертвований для поддержания деятельности электронных католических СМИ. Традиционные коробки для пожертвований на эти цели выставлены в костёлах страны, а теперь пожертвование можно сделать, не выходя из дома.

С 1 ноября 2016 г. в Беларуси начало трансляцию «Радио Мария» (https:// www.radiomaria.by/). Католическую радиостанцию можно слушать круглосуточно на сайте или с приложения к мобильному телефону.

Sacred Space («Пространство молитвы») - это проект информационного центра 
иезуитов в Ирландии, который появился в 1999 году. За короткое время сайт стал многоязычным, и у белорусов тоже появилась возможность реализовать религиозную онлайнпрактику личной молитвы на родном языке (http://www.prastoramalitvy.by/).

8 марта 2019 г. у католиков, которые по уважительным причинам не могут лично присутствовать в храме на пятничном богослужении Великого поста - крестном ходе (в память об остановках Иисуса Христа во время мученического пути на Голгофу), появилась возможность смотреть прямые онлайн-трансляции этого богослужения в одном из костёлов Минска [Кожную пятніцу... web].

Следует отметить, что уже много лет христиане Беларуси (православные и католики) имеют возможность смотреть онлайнтрансляции Рождественских и Пасхальных богослужений из их христианских храмов не только в Интернете, но и на каналах государственного телевидения.

Таким образом, мы можем сделать вывод о том, что религиозные онлайн-практики актуализируются в Беларуси (на примере столичного Минска) достаточно активно. Сфера религиозных практик, на первый взгляд достаточно закрытая от проникновения технического прогресса, на самом деле «обновляется» вместе с обществом в целом, - может быть, не так стремительно, как сферы светской жизни. Тем не менее уже сейчас мы можем утверждать, что средством достижения целей религиозной жизни для священников и их «целевой аудитории» может быть и цифровая активность в сети Интернет.

\section{СПИСОК ЛИТЕРАТУРЫ}

Астахова 2008 - Астахова Л.С. Религиозное действие в контексте повседневности. Казань: Издво Казан. гос. ун-та, 2008.

Астахова 2013 - Астахова Л.С. Динамика современных религиозных практик в структурах повседневности: автореф. дис. ... д-ра филос. наук: 09.00.14. СПб., 2013.

Заславская 2000 - Заславская Т.И. Поведение массовых общественных групп как фактор трансформационного процесса // Мониторинг общественного мнения: экономические и социальные перемены. 2000. № 6. С. 13-18.
Ковалиско 2010 - Ковалиско Н.В. Теория практик, практики и исследование стратификационных порядков // Социология: теория, методы, маркетинг. 2010. № 2. С. 49-63.

Кожную пятніцу... web - Кожную пятніцу ўвечары крыжовы шлях анлайн // https:/catholic.by/3/ news/announcements/7578-kozhnuyupyatnitsu-vechary-kryzhovy-shlyakh-onlajn.

Конева 2018 - Конева А.В. Трансформация религиозных практик в информационную эпоху // Вестник СПбГИК. 2018. № 4. С. 65-72.

Общество web - Общество [Официальный интернет-портал Президента Республики Беларусь ] // http://president.gov.by/ru/society_ru.

Радаев 2003 - Радаев В.В. Обычные и инновационные практики в деятельности российского среднего класса // Мир России. 2003. № 4. С. 89-117.

Религия в Беларуси... web - Религия в Беларуси - от православия к протестантизму? // http:// ostro.by/society/religiya-v-belarusi-otpravoslaviya-k-protestantizmu/.

Русселе, Агаджанян (ред.) 2006 - Русселе К., Агаджанян $A$. (ред.) Религиозные практики в современной России: сб. ст. М.: Новое Издательство, 2006.

Церкви ... web - Церкви в режиме онлайн принимают пожертвования и распространяют Евангелие [Газета Протестант] // http:// www.gazetaprotestant.ru/2017/07/cifrovyetexnologii-prixodyat-v-cerkovnuyu-zhiznxristian-no-ne-vse-zdes-gladko/.

Theodore R. Schatzki 2003 - Theodore R. Schatzki. A New Societist Social Ontology // Philosophy of the Social Sciences. 2003. Vol. 33, № 2. P. 174-202.

\section{REFERENCES}

Astakhova L.S., 2008. Religious action in the context of daily occurrence. Kazan, Kazansk publishing house. state. un-t.

Astakhova L.S., 2013. Dinamik modern religious the practician in structures of daily occurrence: the abstract of the thesis for a degree of the Doctor of Philosophy: 09.00.14. Saint Petersburg.

Zaslavskaya T.I., 2000. Behavior of mass public groups as a factor of transformational process. Monitoring of public opinion: economic and social changes, no. 6, pp 13-18.

Kovalisko N.V., 2010. Theory practician, practicians and research of stratification orders. Sociology: theory, methods, marketing, no. 2, pp. 49-63.

Kozhnuiu piatnitsu ỹvechary - kryzhovy shliakh anlain. URL: http://catholic.by/3/news/ 
announcements/7578-kozhnuyu-pyatnitsuvechary-kryzhovy-shlyakh-onlajn.

Koneva A.V., 2018. Transformation religious the practician during information era. Messenger $S P b G I K$, no. 4, pp. 65-72.

Society. Official Internet portal of the President of Republic of Belarus. URL: http://president.gov.by/ $\mathrm{ru} /$ society_ru.

Radayev V.V., 2003. A common and innovative practice in activity of the Russian middle class. The World of Russia, no. 4, pp. 89-117.

Religion in Belarus - from Orthodoxy to Protestantism? URL: http://ostro.by/society/ religiya-v-belarusi-ot-pravoslaviya-kprotestantizmu/.

Russele K., Agadzhanyan A. (eds.), 2006. Religious practicians in modern Russia. Moscow, New Publishing house.

Churches online accept donations and extend the Gospel. Protestant Newspaper. URL: http:// www.gazetaprotestant.ru/2017/07/cifrovyetexnologii-prixodyat-v-cerkovnuyu-zhiznxristian-no-ne-vse-zdes-gladko/.

Theodore R. Schatzki, 2003. A New Societist Social Ontology. Philosophy of the Social Sciences, vol. 33, no. 2, pp. 174-202.

\section{Information about the Authors}

Dmitry K. Beznjuk, Doctor of Sciences (Sociology), Professor, Leading Researcher, Sociology of Culture Department, Institute of Sociology of the National Academy of Sciences of Belarus, Surganova St., 1/2, 220072 Minsk, Republic of Belarus, mayo-r-r-r@mail.ru, https://orcid.org/0000-0002-3546-3748

Natalya V. Tsybulskaya, Candidate of Sciences (Sociology), Associate Professor, Head of the Sociology of Culture Department, Institute of Sociology of the National Academy of Sciences of Belarus, Surganova St.,1/2, 220072 Minsk, Republic of Belarus, n-tsybulskaya@yandex.by, https:// orcid.org/0000-0003-4521-0653

\section{Информация об авторах}

Дмитрий Константинович Безнюк, доктор социологических наук, профессор, ведущий научный сотрудник отдела социологии культуры, Институт социологии НАН Беларуси, ул. Сурганова, 1/2, 220072 г. Минск, Республика Беларусь, mayo-r-r-r@mail.ru, https://orcid.org/0000-0002-3546-3748

Наталья Васильевна Цыбульская, кандидат социологических наук, доцент, заведующая отделом социологии культуры, Институт социологии НАН Беларуси, ул. Сурганова, 1/2, 220072 г. Минск, Республика Беларусь, n-tsybulskaya@yandex.by, https:/orcid.org/0000-0003-4521-0653 